\title{
Challenges in the Conservation of an Over-Harvested Plant Species with High Socioeconomic Values
}

\author{
Yan Chen $1,2, *\left(\mathbb{D}\right.$, Hong Liu $2,3, * \mathbb{C}$ and Joel Heinen ${ }^{2}$ \\ 1 University of Electronic Science and Technology of China, Zhongshan Institute, No.1 Xueyuan Road, \\ Shiqi District, Zhongshan 528402, China \\ 2 International Center for Tropical Botany and Department of Earth and Environment, \\ Florida International University, 11200 SW 8th Street, Miami, FL 33199, USA \\ 3 Fairchild Tropical Botanic Garden, 11935 Old Cutler Road, Miami, FL 33156, USA \\ * Correspondence: chenyanmail2012@gmail.com (Y.C.); hliu@fiu.edu (H.L.)
}

Received: 28 June 2019; Accepted: 31 July 2019; Published: 2 August 2019

\begin{abstract}
Overexploitation to meet commercial demands has threatened the existence of many species. In theory, one can adopt a portfolio of policies and measures from both the supply (i.e., encourage cultivation while punishing poaching) and demand (i.e., education of consumers) sides to achieve sustainable use. Here we examine the effects of governmental policies and measures towards the utilization of Aquilaria sinensis, a threatened species with high cultural and economic values. We found that, despite national protected status and a suite of government initiatives and granted projects to implement cultivation of the species, poaching persisted and even intensified. From the consumer side, current cultural education related to the species was not coupled with equally strong conservation education, which might have inadvertently reinforced the notion that wild-sourced materials are better, and facilitated a luxury goods-like market for wild products. It appeared that the current government portfolio of initiatives was highly skewed towards utilization, and therefore not effective for promoting the long term ecological persistence of the species. This finding is likely not unique to A. sinensis, nor limited to China. A more balanced portfolio of government initiatives to include stronger and more direct conservation measures towards highly exploited species is needed to achieve sustainable use of this species and related species.
\end{abstract}

Keywords: Aquilaria sinensis; overexploited plants; conservation policy; portfolio of initiatives; NGOs; sustainable use; restoration-friendly

\section{Introduction}

Increasing demand for a wide range of wild plants and animals associated with increasing human needs and populations and, in particular, commercial trade, has led to the overexploitation of many species [1,2]. Globally, overexploitation is the second greatest threat following habitat destruction and alteration, to species survival [3-5]. How to balance species conservation and utilization has been a persistent challenge for many species [6]. On the one hand, putting target species under national or provincial/state protected status to control use is a main conservation tool. On the other hand, farming of wild animals and plants is being used or encouraged in both national and international policy. For example, the Addis Ababa Principles and Guidelines for the Sustainable Use of Biodiversity [7]; Goal 8 in CBD-Biodiversity and the 2030 Agenda for Sustainable Development [8]; and Strategic Goal B, Targets 7 and 18 in the Aichi Biodiversity Targets [9] are all about promoting sustainable use for assumed benefits for local livelihoods and biodiversity conservation. But data supporting or opposing the efficacy of these policies are scarce $[10,11]$. 
Plants constitute the vast majority of species facing over-harvesting [11] and, among them, harvesting for medicinal purposes represents the majority of uses $[3,11]$. Species in the genus Aquilaria, also known as agarwood or incense wood, are part of both Ayurvedic and Traditional Chinese Medicine in South, Southeast and East Asian countries [12]. They are commonly used for the treatment of inflammatory related ailments and diarrhea, as well as for sedative and cardio-protective properties. Agarwood has also had cultural and religious significance for its use in making aromatic materials for religious ceremonies in the Middle East and East Asia for several millennia [12-15].

While agarwood's traditional uses continue in modern times, new applications are being developed; for example, it is now used in the perfume industry [12,16]. How Aquilaria trees are being harvested has also changed. Traditionally, usable agarwood is formed naturally when Aquilaria trees react to mechanical or biological (i.e., by herbivores) injuries to tree trunks. Agarwood can be harvested non-lethally by carving out the oil-rich injured tissues without cutting down the whole trees. In order to increase production, tree trunks are often injured artificially throughout the trunks on naturally growing and planted trees. In addition, the leaves have also been developed to be used in medicines and for other uses $[12,17]$. Extractions from both leaves and heartwood are not limited to medicinal uses; they are also made into incense products, or as fragrances in the production of cosmetics, personal care and ornamental items in China and India (e.g., soaps, shampoos, carved sculptures, beads, bracelets and boxes). Lower-grade wood containing low levels of oil is burned for fumigation purposes and crushed leaves are used as ingredients in biscuits [18], instant noodles, balms and candle wax [19]. In China and India, bark is also used to make paper and fibers for making cloth and rope [20,21]. Harvesting Aquilaria trees is increasingly lethal for the reasons mentioned above, and because illegal harvest in protected areas is often done hastily and without regards to the trees' survival.

Among the 20 recognized species in the genus Aquilaria, four are critically endangered, one is endangered, seven are vulnerable, and the remaining six species are classified as data deficient [22]. One of the major threats to all species in the genus is over-harvesting (Table S1) [22]. This includes A. sinensis, which is listed as vulnerable. Oddly, over-harvesting is not cited as a threat factor in the Chinese Red List. Aquilaria sinensis is endemic to southern China and occurs naturally in Guangdong, Hainan, Guangxi, Fujian, and Hong Kong (Flora of China; Figure 1) [21]. In order to protect the species legally, the Chinese government has placed A. sinensis under the Wild Plants Protection Regulation by putting it on the State Key Protected Plants Category II list in 1999 (State Key Protected Plants Category, First Edition). This means that any legal collection of wild plants (within protected areas or not) is subject to permission by the Forestry Authority at the Provincial level. In addition, to ease poaching pressures on wild trees and to satisfy commercial demand, the Chinese government, along with several other Asian countries, has encouraged the cultivation of Aquilaria species [2,23,24]. A. sinensis is widely cultivated in Guangdong, Hainan and Taiwan provinces in China [25].

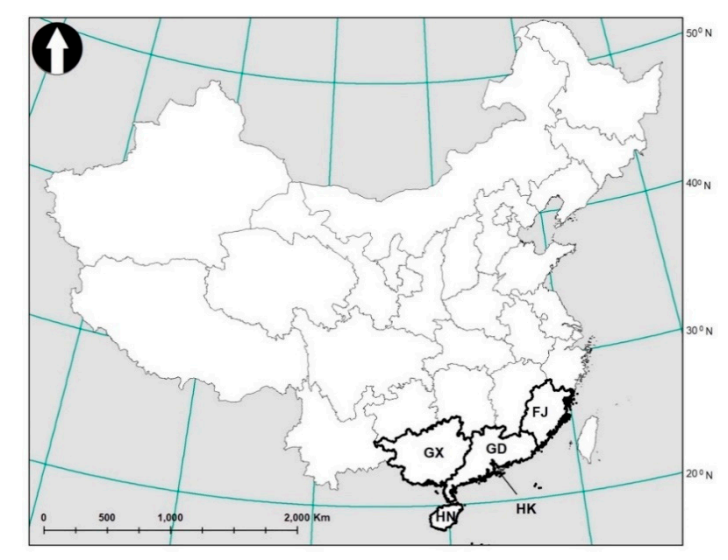

Figure 1. Map of China with indication of natural distribution of $A$. sinensis. Note: GX $=$ Guangxi province, $\mathrm{GD}=$ Guangdong province, $\mathrm{HN}=$ Hainan province, $\mathrm{FJ}=$ Fujian province, $\mathrm{HK}=$ Hong Kong special administration region. 
Even with the above conservation policies and regulations in place, anecdotal accounts suggest that poaching wild $A$. sinensis persists (Figure 2 and Figure S1). The purpose of this study is to exam the data available from different sources in order to understand the conservation challenges facing this species, resulting from its high socioeconomic and cultural values. The objectives of our study are to understand: (1) The current wild population status of $A$. sinensis, (2) the poaching intensity over the past two decades, (3) efforts by the Chinese government to conserve the species, (4) whether commercial cultivation has helped to ease poaching intensity, and (5) the lessons that can be learned to conserve similar plant species with both high cultural and commercial values. Incidentally, although it is part of China, Hong Kong is semi-autonomous and has a different governmental system. As a result, its regulations about, and management of, natural resources are different from those of mainland China. Culturally, however, Hong Kong is similar to the neighboring Guangdong province of China, including in its traditional uses of plants and animals both for foods and medicines. This situation creates an opportunity to contrast conservation practices under similar cultures but different jurisdictions.

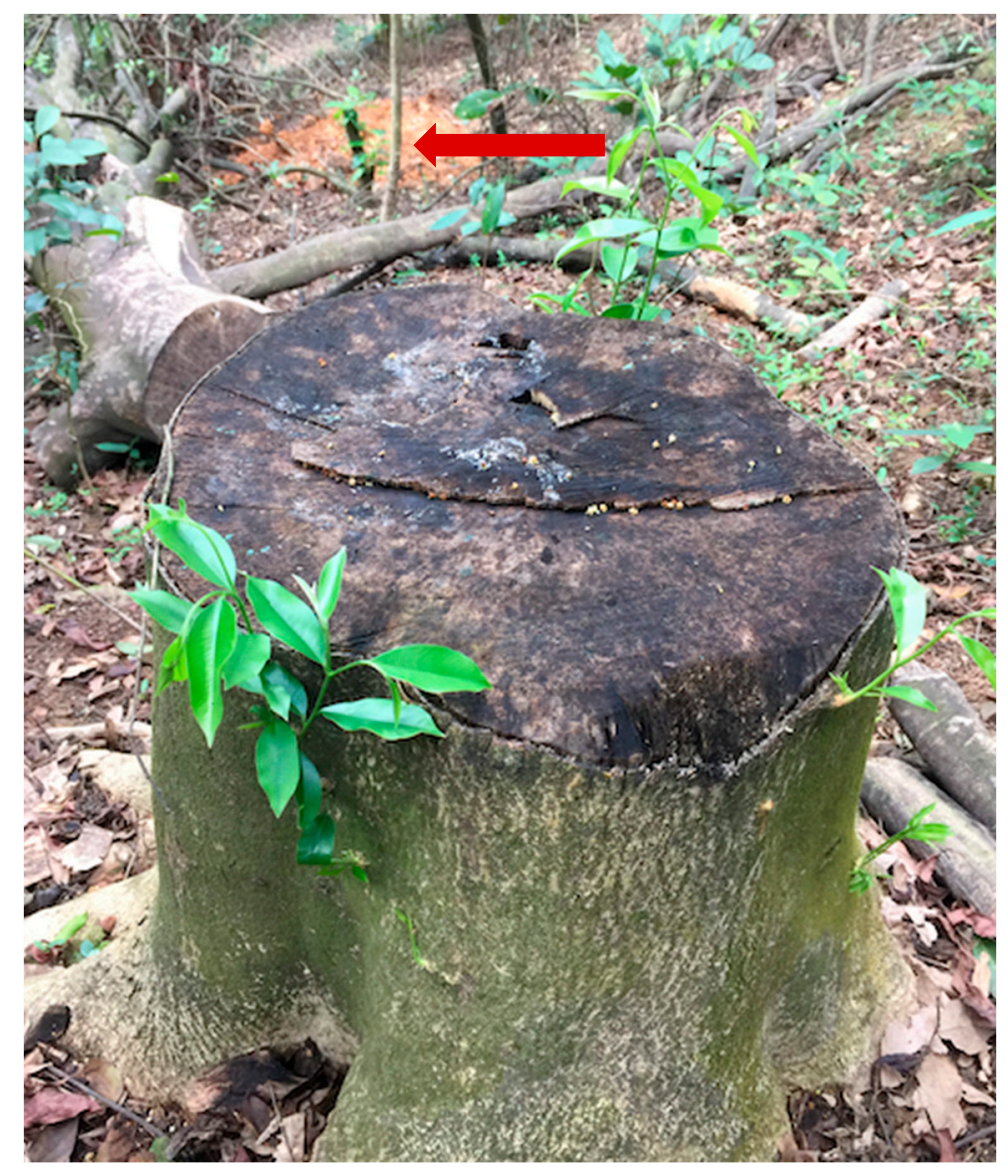

Figure 2. Poaching of A. sinensis in Zhongshan City. Note: The picture was taken on 4 July 2018. The color of the stump and new sprouts indicate that it was cut nearly one year prior to when this image was taken. The upper part of the cut trunk was abandoned nearby. The stump will be excavated when the poachers determine that the resinous compounds have been formed. The arrow points to the location of another stump that has been excavated.

\section{Materials and Methods}

We examined the challenges facing the conservation of $A$. sinensis by reviewing literature to collect data in the following three categories: (1) Wild population status and poaching intensity, (2) government policies and support (such as grants or cultivation initiatives) related to its utilization and conservation, (3) any actions made by conservation entities including non-governmental organizations (NGOs) to promote conservation and/or cultivation of the species. 


\subsection{Population Status and Poaching Intensity}

We used both peer reviewed and grey literature for this study. For literature in English, we used Google and Google Scholar with the following combinations of search terms: "A. sinensis" and "wild" or "wild resource" and "A. sinensis" and "poaching". We also used Google to search for news reports on the species in Chinese, “土沉香” (pronounced tu-chen-xiang). For literature in Chinese, we used the China National Knowledge Infrastructure Database for scholarly papers in Chinese and Baidu.com (the most popular Chinese internet search engine) for articles and news reports. We searched for and recorded poaching information covering the years 2002 to 2018.

We obtained numerous search results from Google and Baidu, which could not all be processed in a reasonable time frame. However, because they are presented in order of relevance of the search terms, we screened the first 100 items of each to determine relevance based on our objectives. We eliminated repeated news items and recorded the following information from relevant news reports: Numbers of poaching cases, damaged trees, prosecuted cases, and arrests.

We obtained poaching information covering the period from 2005 to 2018 in Hong Kong from the website of the Legislative Council of the Hong Kong Special Administrative Region of the People's Republic of China (http://legco.gov.hk). We also obtained poaching information from the Association for the Ecological and Cultural Conservation of Aquilaria sinensis (http://incensetrees.wixsite.com/incensetrees), a Hong Kong based NGO focused on the conservation of the species. This NGO has volunteers who patrol and monitor wild A. sinensis plants in Hong Kong's forests and provid data on the population status and poaching incidences for the period from 2011 to 2018. In contrast, we could not obtain any official poaching information (news reports excluded) from government agencies on mainland China. Nevertheless, we were able to interview two anonymous officials of the Forestry Department of Zhongshan City, Guangdong Province, who provided us with the number of cases prosecuted from that locality.

To determine the degree of reporting and information transparency related to poaching, we compared the numbers of trees injured and prosecuted cases reported by the media and by the NGO with those reported on the government websites for Hong Kong. In Zhongshan City of mainland China where we were able to interview an anonymous forestry official as a key informant, we compared statistics reported by news agencies with those of the key informant.

We used a total of seven key informants who were experts from research institutes or pharmacies specializing in Chinese medicine, to inquire about national medicinal standards and use pattern of A. sinensis, the quality of cultivated products, and general cultivation information. We interviewed them via email or WeChat (a popular Chinese social media platform for personal and group communications, similar to Whatsapp).

\subsection{Government Policies and Funding Related to Domestic Cultivation of the Species}

We compiled information on government policies and funding efforts related to cultivation of A. sinensis using a literature review technique similar to that outlined above, but with the following search terms: "A. sinensis" and "initiatives", "A. sinensis" and "cultivation" or "plantation". To further understand the Chinese government's conservation efforts and other initiatives related to the species, we also searched projects with grants issued by the Ministry of Science and Technology of the People's Republic of China (www.most.gov.cn) and the Departments of Science and Technology of Guangdong, Guangxi, Hainan and Fujian provinces (http://www.gdstc.gov.cn, http://www.gxst.gov.cn, http://dost.hainan.gov.cn, http://kjt.fujian.gov.cn). We searched for grants, projects or initiatives of the National Forestry and Grassland Administration (www.forestry.gov.cn), the Forestry Department (http://www.gdf.gov.cn, http://lyt.hainan. gov.cn, http://www.gxly.cn, http://ffforestry.gov.cn) and the government websites (http://www.gd.gov.cn, http://www.hainan.gov.cn, http://www.gxzf.gov.cn, http://www.fujian.gov.cn), as well as research institutes under the administration of the Chinese Academy of Forestry, especially the Research Institute of Tropical Forestry (http://ky.forestry.gov.cn, http://www.ritf.ac.cn). This covers the four mainland provinces where A. sinensis is native. We also searched granted projects in Hong Kong on the websites of Research Grants Council of the University Grants Committee (www.ugc.edu.hk), the Environment and Conservation 
Fund (http://www.ecf.gov.hk) and initiatives on the Agriculture, Fisheries and Conservation Department website (www.afcd.gov.hk). We eliminated all repeat information from these different searches.

We classified granted projects and other initiatives into the following nine categories: (1) Large-scale cultivation (i.e., promotion of large commercial cultivation); (2) small-scale cultivation (i.e., poverty relief, business startups, demonstration sites for economically valued trees and seedling production); (3) reintroduction/afforestation (i.e., governmental initiatives for conservation, restoring abandoned farmlands to forests); (4) ex situ collections (i.e., efforts to collect the different ecotypes of the species for further commercial utilization); (5) in situ research (i.e., wild resource surveys to gather baseline information for commercial or medical uses); (6) biochemistry research related to analyses of the resinous substance formation, organic compounds and product standard establishment; (7) utilization (i.e., medical use or other uses development); (8) culture development (i.e., tourism and trade surveys, and standard set up for market services); and (9) others (i.e., ecological and biogeographical researches and grants to support conferences centered on A. sinensis cultural developments).

\subsection{Local Conservation Advocacy and Actions}

To understand local non-government conservation efforts, we searched and summarized social organizations related to the species in mainland China and Hong Kong. In China, social organizations are required to register with the Administration of Social Organizations (ASO), which provides a platform to search all social organizations in the country (www.chinapo.gov.cn). We used the term "A. sinensis" in Chinese on this platform. After eliminating repetitive listings, we found 81 organizations. In Hong Kong, social organizations are registered with the Hong Kong Police Force, which posts all organizations on its website (www.police.gov.hk). We did the search of NGOs using the term "A. sinensis" in August 2018. In addition, regarding NGOs in Hong Kong, we interviewed a key informant in Hong Kong who had carried out $A$. sinensis conservation work.

These NGOs were classified into the following six types based on their objectives: (1) Conservation (i.e., NGOs with conservation of wild resources as their primary objective); (2) cultivation (i.e., cooperative associations for developing cultivation, mostly consisted of growers); (3) commercial (i.e., associations serving as platforms for traders and retailers and for production development and commercial communications); (4) culture/ex situ (i.e., associations of Way of Fragrance, art work collections and displays, ex situ collections and garden establishment). We lumped garden establishment and cultural associations together because gardens carry out cultural exhibits and education related to A. sinensis; (5) service (i.e., NGOs that provide services to identify fungi and important compounds of $A$. sinensis and provide advice on applications); (6) multiple objectives (i.e., associations with more than one major objective, mostly focused on cultivation and commercial, cultivation and cultural, cultivation and service, commercial and culture, or culture and service).

\section{Results}

\subsection{Population Status and Poaching Intensity}

\subsubsection{Population Status}

Most research reported that wild populations were in decline and were becoming increasingly rare. In mainland China, only one study [26] reported specific population sizes in several provinces. Based on that study, Guangdong had 70,442 individuals of 20 to 30 years old, Hainan had 59,888 individuals from 2 to 30 years old, and Guangxi had two individuals of about 40 and 100 years old. That work did not report how they obtained these numbers. However, one of our key informants did a field survey in 2015 on the species and found many seedlings and saplings at sites in Guangxi. In Hong Kong, the Association for the Ecological and Cultural Conservation of Aquilaria sinensis (the Hong Kong NGO has monitored populations since 2004) reported that there were less than 300 plants in the wild in 2017. We interviewed two key informants who work at a University in Fujian in a relevant field. Both told us 
that there were no more $A$. sinensis individuals in the wild any more. All are cultivated. We didn't obtain any other information on the wild population in Fujian.

\subsubsection{Population Intensity}

We found 51 news articles that reported on poaching of A. sinensis from 2002 to 2018, with a total of 801 poaching cases and 2080 individual trees injured or killed (Figure 3, detailed information shown in Table S2). Damage to these trees came in different forms; some were cut down entirely, while only part of the trunk was damaged or the bark was striped in others. In addition, there were reports on the poaching of seedlings since 2010 . When poachers were arrested and prosecuted, the number of pieces of wood confiscated were weighted and counted. A total of $1742.7 \mathrm{~kg}$ and 41 pieces of wood were recorded in this manner.
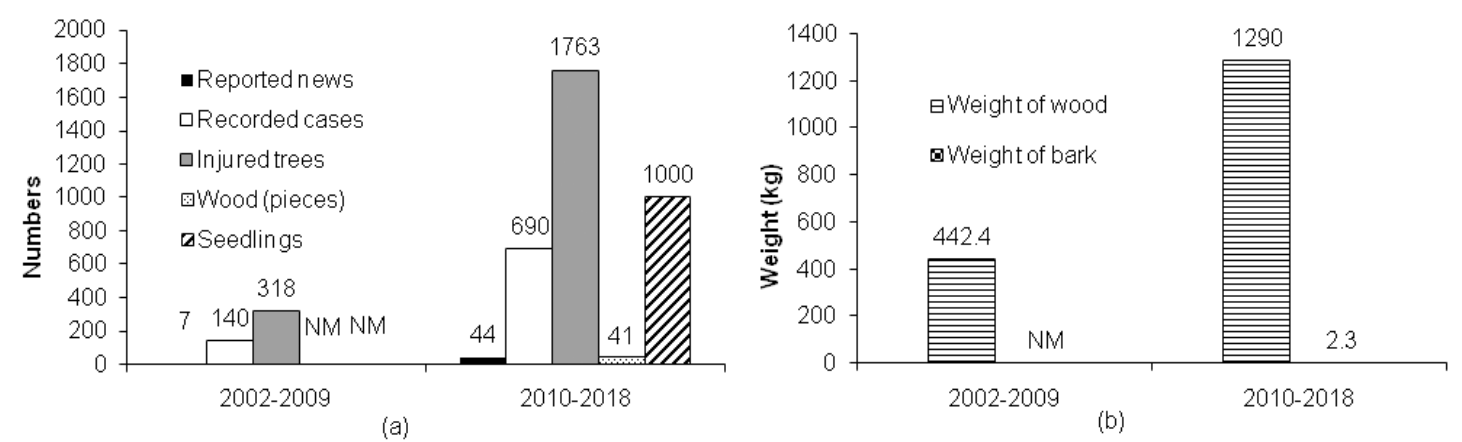

Figure 3. Poaching information between 2002-2009 and 2010-2018. Note: (a) The numbers of reported news, recorded cases, injured trees, pieces of wood and seedlings. (b) The weight of wood and bark. $\mathrm{NM}=$ not mentioned. Hong Kong data are from 2005 to 2018, only the first 7 months were collected in 2018.

According to the key informants and literature surveys, the scale of cultivation increased dramatically in and after 2010. If cultivation and relief of poaching intensity were negatively correlated, one would expect that the number of poaching events to have declined in or after 2010. However, neither the number of news articles on poaching, nor the number of cases reported showed any decline. Specifically, there were only 7 news articles and 139 cases reported over an 8 years period prior to 2010. But there were 44 news articles and 671 cases reported after 2010, which was 6.2 times and 4.8 times higher than those recorded prior to 2010, respectively (Figure 3). In addition to mature trees, as mentioned above, seedlings and saplings were also reported as having been poached in 2011 and 2012.

The majority of poaching reports occurred in Hong Kong (12 news articles) and Guangdong (32 news articles) (Table 1), which accounted for $23.5 \%$ and $62.7 \%$ of the total, respectively. Similarly, the majority of recorded poaching cases (803 cases) was reported in Hong Kong (730 cases) and Guangdong (73 cases), which accounted for $90.1 \%$ and $9.0 \%$, respectively. No poaching incidences were reported in Fujian, and only one poaching case was reported from Guangxi, probably because wild populations of $A$. sinensis were very small in Guangxi by 2002, and no wild populations persist in Fujian, as reported by one key informant.

We compared the prosecution rates of arrests cases (numbers of known prosecution cases per number of reported cases) to see whether they were different between mainland China and Hong Kong. Results showed that the percentage of prosecuted cases was $26.0 \%$ in Hong Kong and $27.6 \%$ in Zhongshan City of Guangdong Province. No data were available in other areas. The number of trees poached recorded by the Hong Kong government website was $48.9 \%$ of that recorded by the Association for the Ecological and Cultural Conservation of Aquilaria sinensis. In contrast, the number of trees poached reported by the news media was $12.1 \%$ of that reported by our key informant (an anonymous official) in Zhongshan city. 
Table 1. Poaching information collected from web searches from 2002 to 2018.

\begin{tabular}{ccccccc}
\hline Districts & $\begin{array}{c}\text { Reported } \\
\text { News }\end{array}$ & $\begin{array}{c}\text { Recorded } \\
\text { Cases }{ }^{1}\end{array}$ & $\begin{array}{c}\text { Injured } \\
\text { Trees }\end{array}$ & $\begin{array}{c}\text { Weight of } \\
\text { Wood (kg) }\end{array}$ & $\begin{array}{c}\text { Wood } \\
\text { (Pieces) }\end{array}$ & Others \\
\hline Hongkong & 12 & 730 & 1463 & 1325.2 & 3 & some seedlings \\
Guangdong & 32 & 73 & 612 & 207.4 & NM & NM \\
Hainan & 4 & 4 & 5 & $\mathrm{NM}$ & 38 & NM \\
Guangxi & 1 & 1 & $\mathrm{NM}$ & $\mathrm{NM}$ & $\mathrm{NM}$ & 1000 seedlings \\
Total & 49 & 708 & 2080 & 1532.6 & 41 & more than 1000 seedlings and 2.3kg bark \\
\hline
\end{tabular}

Note: NM means not mentioned in the news or other records. Hong Kong data were from 2005 to $2018 .{ }^{1}$ The number of the cases were tallied from the reported news.

\subsection{Government Policies and Funding Related to the Species}

The Chinese government has generated many policies, initiatives and grants to promote the use and cultivation of the species. A total of 75 grants were given by the Department of Science and Technology at national, provincial and municipal or county levels in the time period under study. In addition, 128 initiatives were funded by the National Forestry and Grassland Administration and its national and provincial affiliated research academies and institutes (Table S3). Note that only the five provinces, i.e., Guangdong (Figure S2b), Hainan (Figure S2c), Guangxi (Figure S2d), Fujian (Figure S2e) and Hong Kong, where A. sinensis is or was naturally distributed, received or issued funds focused on the species.

The supported projects (203) focused mostly on encouraging cultivation $(71,35.0 \%)$, including large (36 of $203,17.8 \%$ ) and small scale projects (35, 17.2\%), followed by biochemistry of the species $(37,18.2 \%)$, with a smaller percentage focusing on conservation (reintroduction/afforestation, 29, 14.3\%, Figure 4). National and provincial governments showed different patterns of projects. National projects focused on biochemistry ( 24 of 50, 48\%) with no regard to conservation (Figure S2a). Differently, provincial projects mostly focus on cultivation, with a smaller percentage focusing on reintroduction/afforestation, i.e., Guangdong ( 13 of 55, 23.6\%, Figure S2b), Hainan ( 9 of 59, 15.3\%, Figure S2c), Guangxi (2 of 7 , $28.6 \%$, Figure S2d), Fujian (4 of 29, 13.8\%, Figure S2e). In Hong Kong, three projects were recorded, which all supported conservation efforts (Table S3).

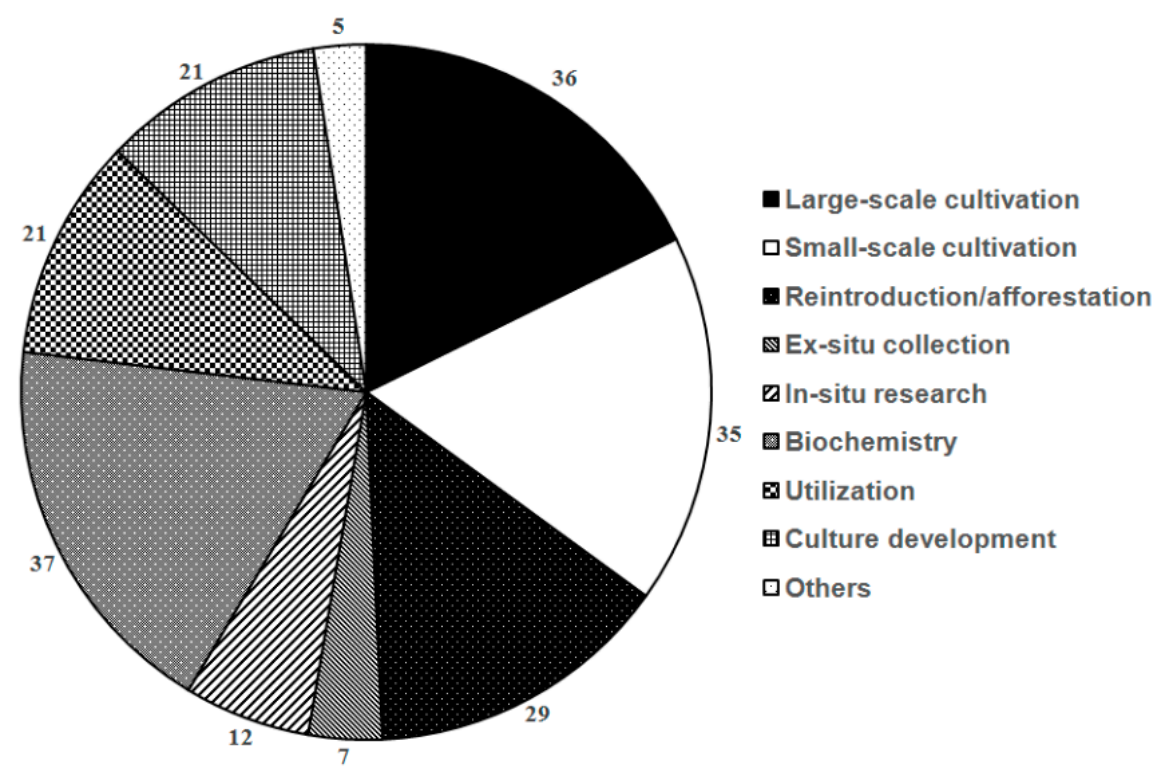

Figure 4. Distribution of the number of grants (combined with initiatives) across the various project categories related to $A$. sinensis at the national level and in the five provinces where $A$. sinensis is native.

Governmental support in the form of initiatives showed different patterns from that of grants (Table S3). Subsidy initiatives focused on encouraging cultivation, including both large and small 
scales and culture development (Hong Kong excluded). We conclude that government grant support has focused on biochemical and utilization research, while government initiatives have focused on cultivation and afforestation.

We were not able to obtain the exact numbers of trees under cultivation from the literature. It appeared that the acreage has been increasing since 2010 to the present. The latest report indicated that 10 million individual trees were planted in agarwood plantations, and 300,000 of them were old enough to produce agarwood (governmental document from the Departments of Science and Technology of Hainan: "Hainan Agarwood Industry Development Plan 2018"). These numbers do not include seedlings provided by government agencies as poverty alleviation initiatives. The Hong Kong government also encouraged cultivation of the species as a conservation measure, and had been planting approximately 10,000 trees per year since 2009. Like many other Asian governments (e.g., Heinen et al. 2001, 2019) [27,28], Hong Kong has developed its own Biodiversity Strategy and Action Plan (2016-2021) following guidelines under the UN Framework Convention on Biological Diversity, which includes conservation efforts such as the augmentation of wild populations, targeting commercially useful species such as $A$. sinensis.

\subsection{NGOs Distribution Patterns}

We found 81 non-governmental social organizations on mainland China and three in Hong Kong that were focused on A. sinensis. Nearly half of the total (40,47.6\%) were culture/ex situ NGOs, focused solely on A. sinensis culture development (Figure 5). In addition, fourteen of the $17 \mathrm{NGOs} \mathrm{with} \mathrm{multiple}$ objectives had the cultural component as one of their objectives. This meant that a total of $64.3 \%$ (54) of NGOs had cultural development among their objectives. Cultural and educational activities carried out by these organizations were to promote use of $A$. sinensis by telling historical and cultural stories to promote product sales. Sixteen NGOs (19.0\%) were of the commercial activities category. An additional six multiple objective NGOs (7.0\%) also included commercial activities as one of their objectives. Therefore, a total of $26.0 \%$ of NGOs had commercial activities as their objective. Both culture and commercial activities involve commerce in some way, hence 76 NGOs $(90.5 \%)$ were directly related to commerce; whereas seventeen NGOs $(20.2 \%)$ were cultivation cooperative associations established to solely $(6,7.1 \%)$ or as part of their objectives $(11,13 \%)$ train farmers to cultivate trees for production. Only two organizations (2.4\%) were conservation NGOs, both of which were in Hong Kong.

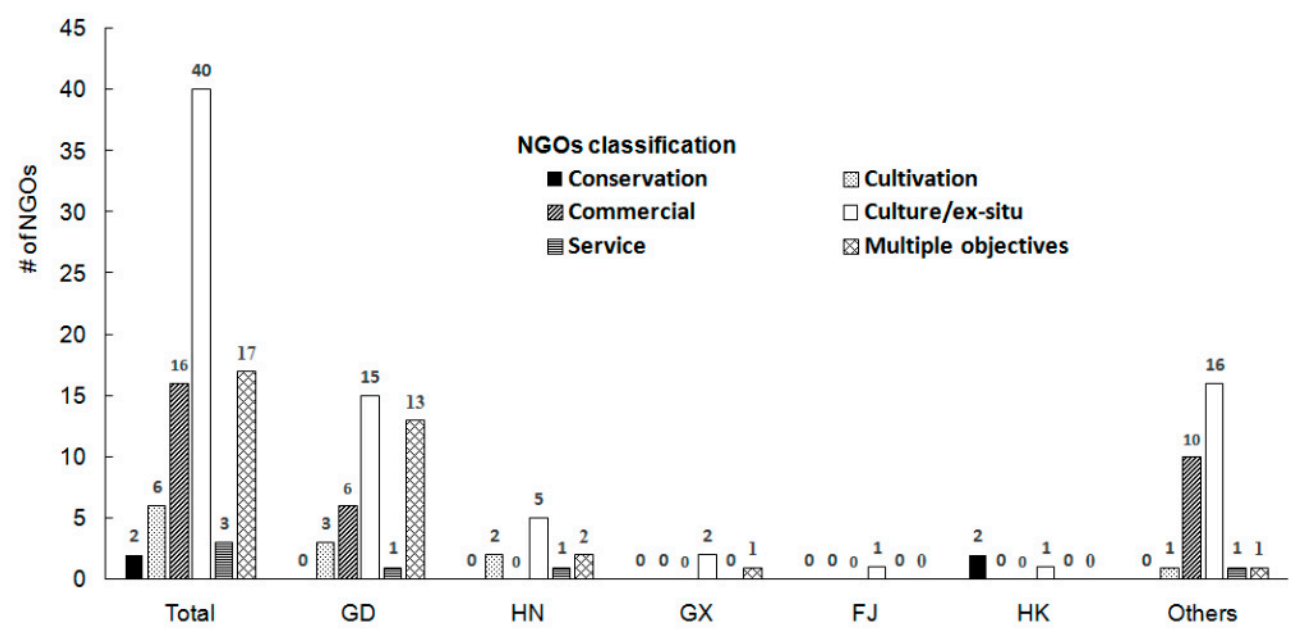

Figure 5. The number of social organizations in different provinces as classified by their respective objectives. Note that "cultivation cooperative associations" are in the "cultivation" category. Note: GD = Guangdong, $\mathrm{HN}=$ Hainan, GX = Guangxi, FJ = Fujian, HK = Hong Kong. The natural distribution of $A$. sinensis is within these five provinces. Others are among the 15 provinces (or equivalent administrative areas) in which A. sinensis is not native. They are: Shanghai, Hunan, Liaoning, Yunnan, Jiangsu, Beijing, Anhui, Hebei, Jiangxi, Guizhou, Shandong, Tianjin, Shanxi, Shichuan and Shaanxi. 


\section{Discussion}

Achieving sustainable use of high-value wild species is a global challenge [11]. In this study, we illustrate this challenge by examining the portfolio of government policies and measures related to the conservation and utilization of $A$. sinensis. Below are our analyses of the results.

\subsection{Population Decline and Persistant Poaching-Does Implementation of Cultivation Help?}

Our review indicated that, within the species native range, natural populations have been extirpated from one province, i.e., Fujiang [26] and had declined to a very small size by 2002 in another (Guangxi) [26]. The population status in the remaining three provinces (i.e., Guangdong, Hainan and Hong Kong) was relatively better. However, based on the key informants accounts, adult trees were extremely rare in those remaining populations, since they were the prime targets for poaching. The only promising evidence for wild population persistence was that surviving adult specimens are very fecund. There appeared to be little barrier to seed germination, which results in abundant seedlings in forests where they occur. This means that, if poaching were to lessen, wild populations could potentially recover on their own in those areas where adult trees remain. However, when seedlings grow to about $10 \mathrm{~cm}$ or more $\mathrm{DBH}$, they tend to be poached, based on the current known exploitation patterns.

The total number of poaching incidents reported in Hong Kong was more than that in the five provinces in mainland China combined, during the same period of time. This by no means indicates that the actual poaching intensity is lower in mainland China. Rather, it likely reflects the fact that information on poaching is not readily available on the governmental or NGO websites in mainland China. Local natural resource management authorities may also be reluctant to release the real numbers of poaching incidents for fear of being seen as ineffective and graded unsatisfactory by the governmental evaluation system (personal communication with a key informant). For example, in Zhongshan City of Guangdong Province, the number of injured trees reported by the county government was only $12.1 \%$ of that reported by the media, and not all known incidents were reported by the media. The insufficient reporting and lack of information sharing on poaching, has likely resulted in over-collecting not being listed as a threat for this species on the IUCN and Chinese Red Lists.

This is in contrast with Hong Kong, where poaching information was more transparent. In addition, civil society in Hong Kong actively monitored the governmental management actions and results. Relying on volunteers, the NGOs recorded nearly double the poaching incidents of that reported by the government. Hong Kong's governmental and socioeconomic environments appear to foster more information transparency and empower citizens to be more engaged in species conservation than that of mainland China. Data transparency and citizen engagement can both facilitate more effective conservation actions including public education. In fact, poachers caught in Hong Kong were not from Hong Kong, but the neighboring province on the mainland (information from Hong Kong governmental website: https://www.info.gov.hk).

Poaching persists despite the wide expansion of cultivation of the species, and it appears to have intensified after the overall scale of cultivation increased nationwide since 2010. This means that cultivation of the species has not alleviated poaching pressures. One major reason for this is the belief that wild plants are of much better quality than cultivated plants, a common belief about medicinal plants in many places (e.g., Heinen \& Shrestha-Acharya 2011 [29]). Chen et al. [25] compared wild and cultivated plants and found that wild agarwood was more complex in organic compounds than cultivated agarwood. This is likely due to differences in resin formation time, with wild agarwood taking several years to form resin while cultivated agarwood takes several months [25,30-34]. These differences have contributed to the preference of users (Personal Communication, Li Yingjiang, Guangxi University, China). Yet, cultivated agarwood can reach pharmaceutical standards specified in the Pharmacopoeia of the People's Republic of China (2015 Edition), which is the country's authority on drug quality and safety. This indicates that replacing the use of wild-sourced agarwood with cultivated agarwood has a valid medicinal basis. 
However, there is another reason for persistent poaching, the existence of a collectors' market in which wild-poached agarwood products are sought and stored, and will only be resold when wild agarwood becomes increasingly rare and prices soar even higher. Under this scenario, to own a piece of wild agarwood becomes a status symbol, as already is the case. Currently, wild agarwood trade bears the hallmark of certain luxury goods markets, involving prestige-seeking consumers [35-37]. Some other current wild animal and plant consumption trends bear this out, e.g., pangolin scales, tiger bone, shark fins, dendrobium orchids, etc. [38,39].

\subsection{What Can the Conservation Community Do to Curb the Trend?}

Currently government incentives and policies towards $A$. sinensis are highly skewed towards utilization. Among all mainland governmental policies and initiatives, $71.9 \%$ of national grants were focused on culture development and commercial cultivation. Only a few were on in situ research ( 9 of total 203 grants and initiatives), and even those included the explicit purpose of further assisting commercial development or medical use. No incentive or policy was on conservation directly. The only grant that specified conservation purposes was issued by the Hong Kong government. Correspondingly, most NGOs related to the species also focused on commercial aspects, with missions to develop exhibits of the cultural aspects of the species and its utilization to promote markets for products.

Government agencies should support more efforts explicitly related to species conservation, especially population augmentation and reintroduction (at sites where populations have been extirpated). This should be done primarily in protected areas. In addition, planting commercially-important species in publicly or privately managed forests where they are native to yield semi-wild income-generating products has been advocated by some authors (e.g., [25,39-41]). Semi-wild cultivation can increase wild agarwood products supply while increasing population sizes, which could help to deflate the luxury markets mentioned above, as more wild-sourced products are made available via appropriate channels to markets [41,42]. At the same time, population genetic studies including samples from remaining wild populations and plantations are needed to guide these reintroductions along with semi-wild cultivation actions to maintain and restore genetic diversity on local and regional scales.

Policy-wise, government documents such as the Red List should acknowledge practices such as wild-harvesting as conservation concerns. Only then, can appropriate measures be implemented, i.e., via ramping up law enforcement efforts selectively where most needed. However, we know of some revenge killings of $A$. sinensis trees by poachers after the government strengthened enforcement. Therefore, enforcement may work best if it is coupled with the reintroduction of restoration friendly cultivation permitted, and other more conventional commercial cultivation practices.

\subsection{The Role of Civil Society and Public Education}

The conservation focused NGOs in Hong Kong functioned both as wild population monitoring forces and information providers to the media and government. They also carried out frequent public education regarding wild resource conservation. Mainland China needs similar NGOs, which may come about by appropriate government policies to encourage their establishment. With regard to public education messages, we wish to make a distinction between species with traditional use histories and cultural values, but with greatly exaggerated medicinal functions (i.e., with functions no more than placebos), from those with proven medicinal functions demonstrated by medical research. The former includes shark fins, rhino horns, tiger bones and pangolin scales. The latter includes many plant products, such as agarwood. Public education campaigns to persuade consumers from using the former could be effective in conservation. However, banning the use of the wild species with scientifically recognized medicinal functions, such as agarwood, is neither likely to work nor desirable for several reasons. Entrenched social values cannot be changed easily [43], and banning high-value products may raise the price further and lead to the involvement of organized crime with the capacity to operate under very strong enforcement efforts [44]. Instead, conservation efforts should be focused on making cultivation operations work for the conservation of the species and for the sustainable utilization of the 
local people (e.g., [45]) and beyond. This strategy will still entail public education, but could be aimed towards providing guidance on consumption choices and consequences of buying wild products sourced in different ways.

As mentioned above, despite cultivated and wild agarwood having chemical differences, they also have a great many similarities [25], and cultivated agarwood can reach prescribed national standards for medicinal applications. According to key informants, some people still prefer the wild plant, even though they know this demand will hurt wild populations. The main reason for this preference appears to be that consumers receive information through public education by the government and NGOs that wild products are better. This could be changed with relative ease to reflect the merits of cultivated products. In addition, semi-natural products cultivated in a way that is conservation friendly should also be promoted (e.g., [39]).

\section{Conclusions}

It is difficult and complicated to conserve high-value species with strong cultural and historical connections to society. The highly skewed government policies and financial support towards utilization and cultural significance shown here may be partially responsible for the persistent demand for, and the price bubble of, wild-sourced agarwood. We recommend concerted and multifaceted measures from both the supplier and consumer sides to achieve sustainable use of the species in question. Conserving and achieving sustainable uses of socially and economically valuable species will not only benefit biodiversity conservation, but also has the potential to improve socioeconomic conditions of rural populations and thus, reduce or remove the need for expensive and draconian law enforcement efforts.

Supplementary Materials: The following are available online at http://www.mdpi.com/2071-1050/11/15/4194/s1. Figure S1a: The picture of freshly injured tree. Figure S1b: Markings made on the trunks of $A$. sinensis by poachers to track tree ages. Figure S2: Distribution of the number of projects (grants and initiatives) across the various project categories related to $A$. sinensis at the national level and in the four provinces where $A$. sinensis is native. Table S1: List of the genus Aquilaria from IUCN. Table S2: The poaching information collected from websites from 2002 to 2018. Table S3: The number of grants given to support scientific projects and initiatives related to $A$. sinensis at the national level and in the five provinces where $A$. sinensis is native.

Author Contributions: Conceptualization, H.L. and Y.C.; methodology, H.L., Y.C. and J.H.; formal analysis, H.L. and Y.C.; investigation, Y.C.; resources, Y.C.; data curation, Y.C.; writing-original draft preparation, Y.C.; writing-review and editing, H.L. and J.H.; supervision, H.L.; project administration, Y.C.; funding acquisition, Y.C.

Funding: This work was funded by the National Natural Science Foundation of China (31401565) and the Zhongshan Science and Technology Research Program for Public Welfare (2018B1023).

Acknowledgments: We thank PuiHan Ho (the chair of Association for the Ecological and Cultural Conservation of Aquilaria sinensis) who provided the incense trees' information in Hong Kong. We also appreciate Jennifer Posseley's help in creating the map. We thank ZiQqiang Pan who provided the pictures of $A$. sinensis.

Conflicts of Interest: The authors declare no conflict of interest. The funders had no role in the design of the study; in the collection, analyses, or interpretation of data; in the writing of the manuscript, or in the decision to publish the results.

\section{References}

1. Ceballos, G.; Ehrlich, P.R.; Barnosky, A.D.; Garcia, A.; Pringle, R.M.; Palmer, T.M. Accelerated modern human-induced species losses: Entering the sixth mass extinction. Sci. Adv. 2015, 1, e1400253. [CrossRef] [PubMed]

2. Maxwell, S.L.; Fuller, R.A.; Brooks, T.M.; Watson, J.E. The ravages of guns, nets and bulldozers. Nature 2016, 536, 143-145. [CrossRef] [PubMed]

3. Schippman, U.; Danna, J.L.; Cunningham, A.B. Impact of Cultivation and Gathering of Medicinal Plants on Biodiversity: Global Trends and Issues; Biodiversity and the ecosystem approach in agriculture, forestry and fisheries. Satellite event on the occasion of the Ninth Regular Session of the Commission on Genetic Resources for Food and Agriculture. Rome; Inter-Departmental Working Group on Biological Diversity for Food and Agriculture: Rome, Italy, 2002. 
4. Abensperg-Traun, M. CITES, sustainable use of wild species and incentive-driven conservation in developing countries, with an emphasis on southern Africa. Biol. Conserv. 2009, 142, 948-963. [CrossRef]

5. Dongol, Y.; Heinen, J.T. Pitfalls of CITES implementation in Nepal: A policy gap analysis. Environ. Manage. 2012, 50, 181-192. [CrossRef] [PubMed]

6. Sutherland, W.J.; Aveling, R.; Brooks, T.M.; Clout, M.; Dicks, L.V.; Fellman, L.; Fleishman, E.; Gibbons, D.W.; Keim, B.; Lickorish, F.; et al. A horizon scan of global conservation issues for 2014. Trends Ecol. Evol. 2014, 29, 15-22. [CrossRef] [PubMed]

7. Secretariat of Convention on Biological Diversity. Addis Ababa Principles and Guidelines 2004. Available online: https://www.cbd.int/sustainable/addis.shtml (accessed on 10 October 2018).

8. Secretariat of Convention on Biological Diversity. Strategic Plan for Biodiversity 2011-2020, Including Aichi Biodiversity Targets 2010. Available online: https://www.cbd.int/sp/targets/default.shtml (accessed on 30 July 2019).

9. Secretariat Convention on Biological Diversity. Biodiversity and the 2030 Agenda for Sustainable Development 2016. Available online: https://www.cbd.int/development/doc/sdg-jul2016-flyer.pdf (accessed on 10 October 2018).

10. Shrestha-Acharya, R.; Heinen, J.T. Emerging policy issues on non-timber forest products in Nepal. Himalaya 2006, 26, 51-54.

11. Liu, H.; Gale, S.W.; Cheuk, M.L.; Fischer, G.A. Conservation impacts of commercial cultivation of endangered and overharvested plants. Conserv. Biol. 2019, 33, 288-299. [CrossRef]

12. Hashim, Y.Y.; Kerr, P.G.; Abbas, P.; Salleh, H.M. Aquilaria spp. (agarwood) as source of health beneficial compounds: A review of traditional use, phytochemistry and pharmacology. J. Ethnopharmacol. 2016, 189, 331-360. [CrossRef]

13. Yamada, I. Aloeswood Forest and the Maritime World. Southeast Asian Stud. 1995, 33, 181-186.

14. Barden, A.; Anak, N.A.; Mulliken, T.; Song, M. Heart of the Matter: Agarwood Use and Trade Cites Implementation for Aquilaria Malaccensis; Traffic international: Cambridge, UK, 2000.

15. Jensen, A.; Meilby, H. Returns from Harvesting a Commercial Non-timber Forest Product and Particular Characteristics of Harvesters and Their Strategies: Aquilaria crassna and Agarwood in Lao PDR. Econ. Bot. 2010, 64, 34-35. [CrossRef]

16. Sitepu, I.R.; Santoso, E.; Siran, S.A.; Turjaman, M. Fragrant Wood Gaharu: When the Wild Can No Longer Provide; Production and Utilization Technology for Sustainable Development of Gaharu in Indonesia: Bogor, Indonesia, 2011.

17. Zhou, M.H.; Wang, H.G.; Suolangiba; Kou, J.P.; Yu, B.Y. Antinociceptive and anti-inflammatory activities of Aquilaria sinensis (Lour.) Gilg. Leaves extract. J. Ethnopharmacol. 2008, 117, 345-350. [CrossRef] [PubMed]

18. Chen, G. Reaping the Bounty of Agar Trees. Available online: http://www.thestar.com.my (accessed on 30 September 2018).

19. Agarwood Products. Available online: http://www.agarharvest.com (accessed on 23 August 2018).

20. Borris, R.P.; Blasko, G.; Cordell, G.A. Ethnopharmacologic and phytochemical studies of the Thymelaeaceae. J. Ethnopharmacol. 1988, 24, 41-91. [CrossRef]

21. Flora of China, Thymelaeaceae, Aquilaria. Available online: http://www.efloras.org/florataxon.aspx?flora id=2\&taxon_id=200014506 (accessed on 10 August 2018).

22. Harvey-Brown, Y. Aquilaria. The IUCN Red List of Threatened Species. Available online: https://www. iucnredlist.org/search?query=aquilaria\&searchType=species (accessed on 29 July 2019).

23. Zich, F.; Compton, J. Agarwood (Gaharu) Harvest and Trade in Papua New Guinea: A Preliminary Assessment; TRAFFIC Oceania, CITES Plants Committee: Canberra, Australia, 2001.

24. Akter, N.; Neelim, A. Agarwood Plantation at BRAC Tea Estate: Introduction, Environmental Factors and Financial Analysis; BRAC Centre: Dhaka, Bangladesh, 2008.

25. Chen, Y.; Yan, T.T.; Shang, L.L.; Fu, Y.J.; Li, G.Y. Distinguish the Wild from Cultivated Agarwood by Using HPLC Combined with PCA. Asian J. Plant Sci. Res. 2017, 7, 23-32.

26. Li, P.P. The study of Aquilaria. Inn. Mong. For. Investig. Des. 2014, 37, 116-118. [CrossRef]

27. Heinen, J.T.; Shukurov, E.; Sadykova, C. Legislative and policy initiatives in biodiversity conservation in Kyrgyzstan. Post-Sov. Geogr. Econ. 2001, 42, 519-543. [CrossRef] 
28. Heinen, J.T.; Baral, N.; Paudel, P.K.; Sah, J.P. On a road to sustainability? A review of a half century of biodiversity conservation successes in Nepal and some thoughts on future needs. In National Parks and Sustainable Future; IntechOpen: London, UK, 2019. [CrossRef]

29. Heinen, J.T.; Shrestha-Acharya, R. The non-timber forest products sector in Nepal: Emerging policy issues in plant conservation and utilization. J. Sustain. For. 2011, 30, 543-562. [CrossRef]

30. Bennett, R.N.; Wallsgrove, R.M. Secondary metabolites in plant defence mechanisms. New. Phytol. 1994, 127, 617-633. [CrossRef]

31. Chen, H.Q.; Yang, Y.; Xue, J.; Wei, J.H.; Zhang, Z.; Chen, H.J. Comparison of Compositions and Antimicrobial Activities of Essential Oils from Chemically Stimulated Agarwood, Wild Agarwood and Healthy Aquilaria sinensis (Lour.) Gilg Trees. Molecules 2011, 16, 4884-4896. [CrossRef] [PubMed]

32. Naef, R. The volatile and semi-volatile constituents of agarwood, the infected heartwood of Aquilaria species. Flavour. Frag. J. 2011, 26, 73-87. [CrossRef]

33. Liu, Y.Y.; Chen, H.Q.; Yang, Y.; Zhang, Z.; Wei, J.; Meng, H.; Chen, W.; Feng, J.; Gan, B.; Chen, X.; et al. Whole-tree Agarwood-Inducing Technique: An Efficient Novel Technique for Producing High-Quality Agarwood in Cultivated Aquilaria sinensis Trees. Molecules 2013, 18, 3086-3106. [CrossRef] [PubMed]

34. Yang, D.L.; Wang, H.; Guo, Z.K.; Li, W.; Mei, W.L.; Dai, H.F. Fragrant agarofuran and eremophilane sesquiterpenes in agarwood 'Qi-Nan' from Aquilaria sinensis. Phytochem. Lett. 2014, 8, 121-125. [CrossRef]

35. Brinberg, D.; Plimpton, L. Self-Monitoring and Product Conspicuousness on Reference Group Influence. Adv. Consum. Res. 1986, 13, 297-300.

36. Vigneron, F.; Johnson, L.W. A Review and a Conceptual Framework of Prestige-Seeking Consumer Behavior. Acad. Mark. Sci. Rev. 1999, 1, 1-15.

37. Gault, A.; Meinard, Y.; Courchamp, F. Consumers' taste for rarity drives sturgeons to extinction. Conserv. Lett. 2008, 1, 199-207. [CrossRef]

38. Challender, D.W.S.; MacMillan, D.C. Poaching is more than an enforcement problem. Conserv. Lett. 2014, 7, 484-494. [CrossRef]

39. Liu, H.; Luo, Y.B.; Heinen, J.T.; Bhat, M.; Liu, Z.J. Eat your orchid and have it too: A potentially new conservation formula for Chinese epiphytic medicinal orchids. Biodivers. Conserv. 2014, 23, 1215-1228. [CrossRef]

40. Ashton, M.S.; Gunatilleke, I.A.U.N.; Gunatilleke, C.V.S.; Tennakoon, K.U.; Ashton, P.S. Use and cultivation of plants that yield products other than timber from South Asian tropical forests, and their potential in forest restoration. For. Ecol. Manag. 2014, 329, 360-374. [CrossRef]

41. Schmidt, J.P.; Cruse-Sanders, J.; Chamberlain, J.L.; Ferreira, S.; Young, J.A. Explaining harvests of wild-harvested herbaceous plants: American ginseng as a case study. Biol. Conserv. 2019, 231, 139-149. [CrossRef]

42. Frey, G.E.; Chamberlain, J.L.; Prestemon, J.P. The potential for a backward-bending supply curve of non-timber forest products: An empirical case study of wild American ginseng production. Forest Policy Econ. 2018, 97, 97-109. [CrossRef]

43. Manfredo, M.J.; Bruskotter, J.T.; Teel, T.L.; Fulton, D.; Schwartz, S.H.; Arlinghaus, R.; Oishi, S.; Uskul, A.K.; Redford, K.; Kitayama, S.; et al. Why social values cannot be changed for the sake of conservation. Conserv. Biol. 2016, 31, 772-780. [CrossRef]

44. Tensen, L. Under what circumstances can wildlife farming benefit species conservation? Glob. Ecol. Conserv. 2016, 6, 286-298. [CrossRef]

45. Heinen, J.T. Applications of human behavioral ecology to wildlife conservation and utilization programmes in developing countries. Oryx 1995, 29, 178-186. [CrossRef]

(C) 2019 by the authors. Licensee MDPI, Basel, Switzerland. This article is an open access article distributed under the terms and conditions of the Creative Commons Attribution (CC BY) license (http://creativecommons.org/licenses/by/4.0/). 